\title{
Factors Contributing to Diarrheal Diseases among Children Less than Five Years in Nyarugenge District, Rwanda
}

\author{
Jean Nsabimana ${ }^{1 *}$, Connie Mureithi ${ }^{1}$ and Michael Habtu ${ }^{2}$
}

${ }^{1}$ Department of Public Health, School of Health Sciences, Mount Kenya University, Kigali, Rwanda

${ }^{2}$ Department of Nursing, School of Health Sciences, Mount Kenya University, Kigali, Rwanda

*Corresponding author: Habtu M, Department of Public Health, School of Health Sciences, Mount Kenya University, P .O. Box 5826, Kigali, Rwanda, T el: +250784460645L; Fax: +2424606245; E-mail: mikel.habtu@gmail.com

Received date: June 02, 2017; Accepted date: June 15, 2017; Published date: June 30, 2017

Copyright: (C 2017 Habtu M, et al. This is an open-access article distributed under the terms of the Creative Commons Attribution License, which permits unrestricted use, distribution, and reproduction in any medium, provided the original author and source are credited.

\section{Abstract}

Background: The burden of diarrheal diseases among children is by far more in low and middle-income countries where it is the second leading cause of deaths in children under 5 years. In Rwanda, it is a third leading cause of childhood morbidity and mortality where it counts $15 \%$ of deaths.
\end{abstract}

Objective: The aim of this study was to determine factors associated with diarrheal diseases among children less than five years in Nyarugenge district, Rwanda.

Methodology: The study was descriptive cross-sectional. Multi stage sampling technique whereby in the first stage 6 health facilities were selected randomly and in the second stage 359 respondents were selected systematically. A Structured pre-tested questionnaire was used to collect data. Pearson's chi-square test $(p<0.05)$ and odds ratio with corresponding $95 \%$ confidence interval were used to establish the association between the dependent variable and independent variables.

Results: The 2 week period prevalence of diarrhea among less than five children was $26.7 \%$. Factors independently associated with diarrheal diseases occurrence were: children whose mothers/caretakers had never attended school $(\mathrm{aOR}=3.76 ; 95 \% \mathrm{Cl}=1.26-11.24 ; \mathrm{p}=0.018)$ and attended primary $(\mathrm{aOR}=2.94 ; 95 \% \mathrm{Cl}=1.04-8.28$; $\mathrm{p}=0.042$ ) compared to those who attended tertiary level of education; children who had not vaccinated for Rota virus (aOR=8.11;95\% Cl: 1.84-35.70; $\mathrm{p}=0.006)$; mothers/caretakers who reported presence of feces around their houses $(\mathrm{aOR}=2.02 ; 95 \% \mathrm{Cl}=1.22-3.35 ; \mathrm{p}=0.006)$ and children living in earthen floor houses $(\mathrm{aOR}=1.76 ; 95 \% \mathrm{Cl}: 1.05-2.96$; $\mathrm{p}=0.031$ ) compared to those living in a cement floors.

Conclusion: The prevalence of diarrhea was high compared to national level. Children whose mothers/ caretakers had never attended and attended primary school; children who were not vaccinated for Rota virus; children living around houses where feaces present and children living in earthen floors were significantly associated with diarrhea. Therefore, we recommend that health education on hygiene. Rota virus vaccination and awareness on environment sanitation should be strengthened to reduce childhood diarrhea.

Keywords: Diarrheal diseases; Hygiene; Multi-stage sampling technique; Socio-demographic

\section{Introduction}

Diarrhoeal diseases are major public health problems especially in children in developing countries [1]. Globally, diarrhoea remains the second most common cause of death among children under five years [2]. There are an estimated 1.7 billion cases of diarrhoea with an average of 2.9 episodes/child/year, and an estimated 1.87 million deaths among children under five years [3]. It constitutes a major burden in low and middle-income countries (LMIC) where it is the second leading cause of death in children under 5 years of age with 90\% of all diarrhea-related deaths [4]. According to World Health Organization (WHO), Africa and south-East Asia regions have $78 \%$ of diarrheal deaths among children less than five years [5]. Children are affected by diarrhea mainly due to poor environmental sanitation and hygiene, inadequate water supplies and poverty [5]. Assessing the contributing factors for diarrheal disease requires knowledge about interactions between socio demographic, socio-economic, behavioral, and environmental factors.

In Ethiopia the prevalence of diarrheal disease among under-five children in a 2 -week period was reported $31.0 \%$ in Arba Minch District [6], 26.1\% in Hadaleala District [7], 24.9\% in northwest Ethiopia [8], 22.5\% in the eastern part of Ethiopia [9], 19.6\% in a rural area of southern Ethiopia [10] and 18.0\% in Mecha District [11]. There are different factors associated with occurrence of diarrhea among children less than five years and these differ from place to place. A study done in Kenya showed that, six factors were independently associated with diarrheal diseases, occupation of the parent/ guardian, care taker not washing hands after changing napkins, child drank untreated water from the river, child not exclusively breastfed, child did not wash hands before eating and after visiting toilet [12].

In Rwanda, according to National Institute of Statistics of Rwanda (2015), prevalence of children under five years who had symptoms of 
diarrhea in the two weeks preceding the survey was $12 \%$. This was higher than acute respiratory infections, among children with symptoms of diarrhea and percentage who sought treatment from a health facility/ provider was $44 \%$ more than previous surveys $[13,14]$. According to records from Nyarugenge district by Rwanda Health Management Information System (RHMIS), diarrheal diseases among children less than five years attending Nyarugenge districts health centers was nearly $40 \%$. However, there is limited study about factors associated with diarrheal diseases in the study area.

\section{Materials and Methods}

\section{Study design and setting}

We carried out a descriptive cross-sectional study in Nyarugenge district, Rwanda. The study area was Nyarugenge district located in Kigali city, Rwanda. Nyarugenge district is divided into 10 sectors: Gitega, Kanyinya, Kigali, Kimisagara, Mageragere, Muhima, Nyakabanda, Nyamirambo, Nyarugenge and Rwezamenyo. The district has ten (10) health centers, 192 nurses, (1 nurse for 1, 468.75 inhabitants), 20 doctors (1 doctor for 14,100 inhabitants).

\section{Study population and sampling techniques}

The study population in this study was all mothers/caretakers with children less than five years, resided in the area for at least six months and consented to participate. Multi-stage sampling technique was used. In the first stage, 6 health facilities were selected randomly. In the second stage, children less than five years were selected systematically from each selected heath facility. The children were selected from the outpatient department of the respective health facilities. The number of respondents in each selected health facilities were allocated proportionally based on the previous month visited to the health facilities. The first participant in each health facility was selected using simple random sampling technique from the first 4 visitors thereafter every 4 th was selected as they come to the health facility.

\section{Sample population}

The sample size for this study was determined using a single population proportion formula $(n=Z 2 \alpha / 2 * P(1-P) / d 2)$ by considering the following assumptions: $\mathrm{Z}$ is the standard normal deviate that corresponds to $95 \%$ confidence interval, $d$ is the degree of precision (5\%), $\mathrm{p}=\mathrm{A}$ prevalence of diarrhea obtained from a study done in Burundi was used (32.6\%) [15]. After adding $10 \%$ non response rate, the sample size calculated was 367 .

\section{Data collection method}

Interviewer administered questionnaire developed based on WHO Core questionnaires related to diarrhea. But it was modified for cultural specificity. The questionnaire was designed in English and then translated into Kinyarwanda. Pretest was done in $5 \%$ of the sample size and the data was collected by trained research assistants. The result of the pretest was used to correct some unclear questions. The questionnaire was divided into the following sections: (1) demographic and socio-economic information, (2) information of the index of the children and (3) environmental factors.

\section{Measurement of dependent variable}

Childhood diarrheal disease, the dependent variable of this study, was defined as having three or more loose or watery stools in 24 hours $[15,16]$ in the previous 2 weeks of data collection. The prevalence of diarrhoea was calculated using the number of children who reportedly had at least one episode of diarrhea within the preceding two weeks of the data collection as numerator (96) and the overall number (359).

\section{Data management and analysis}

Data were checked daily for completeness for accuracy. The data from the questionnaires were then entered into a computer designed using MS-excel application. The data were analysed by using Statistical Package for Social Science [SPSS] Version 22. Descriptive analysis was computed whereby proportion/percentages and frequency were calculated. Pearson's chi-square test and odds ratio with corresponding 95\% confidence interval were computed to establish the association between the dependent variable (diarrhoea status) and independent variables. Variables significant (less than 0.05 ) at bivariate analysis were considered together in multivariate analysis by specifying 'backward LR' method. The level of statistical significance set at pvalue $<0.05$ and $95 \%$ CI without including ORs of one in between were considered significant.

\section{Results}

\section{Socio-demographic characteristics of the children according to diarrhea status}

Table 1 shows the distribution of selected socio-demographic characteristics of children and diarrheal diseases. The prevalence of diarrheal diseases was found to be $26.7 \%$. The ages of the children ranged from 1 month to 59 months. The mean age of the children was 16.6 months with a standard deviation of 9.7 months. Highest percentage (47.9\%) of the children were within the age category of 13 to 24 months followed by $34 \%$ within 1 to 12 months. However, this was not significant. Females were more (53.2\%) than males $46.8 \%$ and the proportion of diarrhea was more among males (31.0\%) compared to females $(23.0 \%)$ but this was not statistically significant. Almost all children (98.3\%) had ever breastfed. Similarly, large percentage (97.5\%) of the children had received Rota virus vaccines and this was significant where children who were not vaccinated for Rota virus (66.7\%) $(\mathrm{OR}=5.78 ; 95 \% \mathrm{CI}: 1.42-23.58 ; \mathrm{p}=0.015)$ had more risk of developing diarrheal diseases than to those who were vaccinated (25.7\%).

\begin{tabular}{|l|l|l|l|l|l|}
\hline Variables & Diarrhea, $n(\%)$ & No diarrhea, $n(\%)$ & Total, $n(\%)$ & COR (95\% CI ) & X2 test \\
\hline Child age value* & & & \\
\hline $1-12$ months & $31(25.4 \%)$ & $91(74.6 \%)$ & $122(34)$ & $2.04(0.43-9.64)$ & 0.366 \\
\hline
\end{tabular}


Citation: Habtu M, Nsabimana J, Mureithi C (2017) Factors Contributing to Diarrheal Diseases among Children Less than Five Years in Nyarugenge District, Rwanda. J Trop Dis 5: 238. doi:10.4172/2329-891X.1000238

Page 3 of 8

\begin{tabular}{|c|c|c|c|c|c|}
\hline 13-24 months & $53(30.8 \%)$ & $119(69.2 \%)$ & $172(47.9)$ & $2.67(0.58-12.36)$ & 0.208 \\
\hline 25-36 months & $10(19.6 \%)$ & $41(80.4 \%)$ & $51(14.2)$ & $1.46(0.28-7.61)$ & 0.651 \\
\hline 37-59 months & $2(14.3 \%)$ & $12(85.7 \%)$ & $14(3.9)$ & Reference & \\
\hline \multicolumn{6}{|c|}{ Gender of the child } \\
\hline Male & $52(31.0 \%)$ & $116(69.0 \%)$ & $168(46.8)$ & $1.50(0.94-2.40)$ & 0.091 \\
\hline Female & $44(23.0 \%)$ & $147(77.0 \%)$ & 191(53.2) & Reference & \\
\hline \multicolumn{6}{|c|}{ Ever breastfeeding of the child } \\
\hline Yes & $96(27.2)$ & $257(72.8)$ & $353(98.3)$ & Reference & \\
\hline No & $0(0.0)$ & $6(100.0)$ & $6(1.7)$ & UD & 0.136 \\
\hline \multicolumn{6}{|c|}{ Weather received rota virus vaccine } \\
\hline Yes & $90(25.7 \%)$ & $260(74.3 \%)$ & $350(97.5)$ & Reference & \\
\hline No & $6(66.7 \%)$ & $3(33.3 \%)$ & $9(2.5)$ & $5.78(1.42-23.58)$ & 0.015 \\
\hline
\end{tabular}

Table 1: Socio-demographic characteristics of the children according to diarrhea status.

Socio-demographic and socio-economic characteristics of mothers/caretakers by children who had diarrhea $(n=96)$ and had no diarrhea $(n=263)$

About half (49.9\%) of the mothers/caretakers were within the age category of 18 to 25 followed by $40.1 \%$ aged between 26 to 32 years. Majority of the respondents $(85.2 \%)$ were mothers to the children while the remaining $(14.8 \%)$ were caretaker or guardian. Most of the mothers/caretakers (84.4\%) were married and majority (77.2\%) were from urban settings. Similarly, majority $(81.9 \%)$ of the mothers/ caretakers were Christian followers. However, these variables were not significant with diarrhea occurrence among children (Table 2).

Regarding level of education, the highest percentage $(40.7 \%)$ attended primary education whereas only (9.5\%) attained tertiary level of education. This was statistically significant with diarrhea occurrence among children Children whose mothers/caretakers had never attended school (39.4\%) $(\mathrm{OR}=3.77 ; 95 \% \mathrm{CI}=1.29-10.99 ; \mathrm{p}=0.015)$ and attended primary level of education (32.9\%) $\quad(\mathrm{OR}=2.84$; $95 \% \mathrm{CI}=1.04-7.80 ; \mathrm{p}=0.043$ ) had more risk of developing diarrheal diseases in the last two weeks compared to those who had tertiary level of education (14.7\%). Similarly, the highest percentage (41.8\%) of the mothers/caretakers were self-employed and this was significant with diarrhea occurrence. Children whose mothers/caretakers were without job $(31.7 \%)(\mathrm{OR}=2.48$; 95\%CI: 1.19-5.19; $\mathrm{p}=0.015)$ had more risk of developing diarrheal diseases compared to those whose mothers/ caretakers were government employee (15.7\%) (Table 2).

\begin{tabular}{|c|c|c|c|c|c|}
\hline \multirow[t]{2}{*}{ Variables } & \multirow{2}{*}{$\begin{array}{l}\text { Diarrhea, } \\
\text { n (\%) }\end{array}$} & \multirow[t]{2}{*}{ No diarrhea, $\mathbf{n}(\%)$} & \multirow{2}{*}{$\begin{array}{l}\text { Total, } \\
\text { n (\%) }\end{array}$} & \multirow[t]{2}{*}{$\operatorname{COR}(95 \% \mathrm{CI})$} & $\mathrm{X}^{2}$ test \\
\hline & & & & & p value ${ }^{*}$ \\
\hline \multicolumn{6}{|c|}{ Age of mothers/caretakers in years } \\
\hline $18-25$ & $61(34.1 \%)$ & $118(65.9 \%)$ & $179(49.9)$ & $1.81(0.78-4.21)$ & 0.169 \\
\hline $26-32$ & $27(18.8 \%)$ & $117(81.2 \%)$ & $144(40.1)$ & $0.81(0.33-1.97)$ & 0.638 \\
\hline $33-40$ & $8(22.2 \%)$ & $28(77.8 \%)$ & $36(10.0)$ & Reference & \\
\hline \multicolumn{6}{|c|}{ Relationship to the child } \\
\hline Mother & $79(25.8 \%)$ & $227(74.2 \%)$ & $306(85.2)$ & Reference & \\
\hline $\begin{array}{l}\text { Caretaker/ } \\
\text { guardian }\end{array}$ & $17(32.1 \%)$ & $36(67.9 \%)$ & $53(14.8)$ & $1.36(0.72-2.55)$ & 0.343 \\
\hline \multicolumn{6}{|c|}{ Residence of mothers/caretakers } \\
\hline Urban & $77(27.8 \%)$ & $200(72.2 \%)$ & $277(77.2)$ & $1.28(0.72-2.27)$ & 0.406 \\
\hline
\end{tabular}


Citation: Habtu M, Nsabimana J, Mureithi C (2017) Factors Contributing to Diarrheal Diseases among Children Less than Five Years in Nyarugenge District, Rwanda. J Trop Dis 5: 238. doi:10.4172/2329-891X.1000238

Page 4 of 8

\begin{tabular}{|c|c|c|c|c|c|}
\hline Rural & 19(23.2\%) & 63(76.8\%) & $82(22.8)$ & Reference & \\
\hline \multicolumn{6}{|c|}{ Marital status of mothers/caretakers } \\
\hline Married & $86(28.4 \%)$ & $217(71.6 \%)$ & $303(84.4)$ & $1.98(0.85-4.63)$ & 0.114 \\
\hline Single & $3(21.4 \%)$ & $11(78.6 \%)$ & $14(3.9)$ & $1.36(0.30-6.19)$ & 0.688 \\
\hline $\begin{array}{l}\text { Separated/ } \\
\text { widowed }\end{array}$ & $7(16.7 \%)$ & $35(83.3 \%)$ & $42(11.7)$ & Reference & \\
\hline \multicolumn{6}{|c|}{ Religion of mothers/caretakers } \\
\hline Christian & $82(27.9 \%)$ & $212(72.1 \%)$ & $294(81.9)$ & Reference & \\
\hline Muslim & $10(18.9 \%)$ & $43(81.1 \%)$ & $53(14.8)$ & $0.60(0.29-1.25)$ & 0.174 \\
\hline Others & $4(33.3 \%)$ & $8(66.7 \%)$ & $12(3.3)$ & $1.29(0.38-4.41)$ & 0.682 \\
\hline \multicolumn{6}{|c|}{ Level of education of mothers/caretakers } \\
\hline Never attended school & $26(39.4 \%)$ & $40(60.6 \%)$ & $66(18.4)$ & $3.77(1.29-10.99)$ & 0.015 \\
\hline Primary & $48(32.9 \%)$ & $98(67.1 \%)$ & $146(40.7)$ & $2.84(1.04-7.80)$ & 0.043 \\
\hline Secondary & $17(15.0 \%)$ & $96(85.0 \%)$ & $113(31.5)$ & $1.03(0.35-3.03)$ & 0.961 \\
\hline Tertiary & $5(14.7 \%)$ & $29(85.3 \%)$ & $34(9.5)$ & Reference & \\
\hline \multicolumn{6}{|c|}{ Occupation of the mother/caretaker } \\
\hline Government employee & $11(15.7 \%)$ & $59(84.3 \%)$ & $70(19.5)$ & Reference & \\
\hline Self employed & $41(27.3 \%)$ & $109(72.7 \%)$ & $150(41.8)$ & $2.02(0.97-4.22)$ & 0.062 \\
\hline Jobless & $44(31.7 \%)$ & $95(68.3 \%)$ & $139(38.7)$ & $2.48(1.19-5.19)$ & 0.015 \\
\hline
\end{tabular}

Table 2: Socio-demographic and socio-economic characteristics of mothers/caretakers by children who had diarrhea ( $\mathrm{n}=96)$ and had no diarrhea $(n=263)$.

\section{Environmental factors stratified by diarrhea occurrence among children}

Table 3 summarizes environmental characteristics of the household stratified by diarrhea occurrence among children. The table shows that there was almost equal distribution between natural earth floor $(51.8 \%)$ and cement floor (48.2\%). This was significantly associated with diarrhea occurrence among children. Children living in soil/ sand/mud floor houses had more risk of diarrhea $(32.8 \%)(\mathrm{OR}=1.92$; 95\%CI: $1.19-3.11 ; \mathrm{p}=0.007)$ compared to those living in a cemented floor (20.2\%). About half (49.6\%) of the respondents indicate presence of feaces around the house and this was a significant factor for diarrhea occurrence. Children whose mothers/caretakers who reported presence of feces around the house had significantly increased risk of developing diarrheal diseases (33.1\%) (OR=1.93; 95\%CI=1.20-3.11; $\mathrm{p}=0.007)$ compared to those who indicated otherwise $(20.4 \%)$.
Majority of the mothers/caretakers indicate that most (93.3\%) of the houses were constructed with metal/iron sheet. About half of the mothers/caretakers (51\%) claimed that they had three rooms followed by $31.2 \%$ with two rooms. Majority $(61 \%)$ indicate that they did not have hand washing facilities. All the mothers/caretakers reported that they had latrines and more than half (58.8\%) were sharing with neighbors. With respect to source of water, $82.7 \%$ were using piped and/or public taps, $11.1 \%$ get water from unprotected well/spring, $3.1 \%$ were using from protected well/spring and 3.1\% from rivers/lakes. Almost all the mothers/caretakers (95.5\%) indicated that they did not have any livestock in the family. Majority (69.6\%) of the mothers/ caretakers did not own any agricultural land. However, these variables were not significant with diarrhea occurrence among children.

\begin{tabular}{|c|c|c|c|c|c|}
\hline \multirow[t]{2}{*}{ Variables } & \multirow{2}{*}{$\begin{array}{l}\text { Diarrhea, } \\
\text { n (\%) }\end{array}$} & \multirow[t]{2}{*}{ No diarrhea, n (\%) } & \multirow[t]{2}{*}{ Total, $\mathbf{n}(\%)$} & \multirow[t]{2}{*}{$\operatorname{COR}(95 \% \mathrm{Cl})$} & $x^{2}$ test \\
\hline & & & & & p value ${ }^{*}$ \\
\hline \multicolumn{6}{|c|}{ Type of the floor material of living house } \\
\hline Earthen & $61(32.8 \%)$ & $125(67.2 \%)$ & $186(51.8)$ & $1.92(1.19-3.11)$ & 0.007 \\
\hline
\end{tabular}


Citation: Habtu M, Nsabimana J, Mureithi C (2017) Factors Contributing to Diarrheal Diseases among Children Less than Five Years in Nyarugenge District, Rwanda. J Trop Dis 5: 238. doi:10.4172/2329-891X.1000238

Page 5 of 8

\begin{tabular}{|c|c|c|c|c|c|}
\hline Cement & $35(20.2 \%)$ & $138(79.8 \%)$ & $173(48.2)$ & Reference & \\
\hline \multicolumn{6}{|c|}{ Type of roof material of living house } \\
\hline Metal/iron sheet & $87(26.0 \%)$ & $248(74.0 \%)$ & 335(93.3) & Reference & \\
\hline Thatched & $0(0.0 \%)$ & $3(100.0 \%)$ & $3(0.8)$ & UD & 0.999 \\
\hline Tile & $9(42.9 \%)$ & $12(57.1 \%)$ & $21(5.8)$ & $2.14(0.87-5.25)$ & 0.097 \\
\hline \multicolumn{6}{|c|}{ Number of rooms in the house } \\
\hline One to two rooms & $40(33.6 \%)$ & $79(66.4 \%)$ & $119(33.1)$ & $2.12(0.99-4.53)$ & 0.053 \\
\hline Three rooms & $45(24.6 \%)$ & $138(75.4 \%)$ & $183(51.0)$ & $1.36(0.65-2.86)$ & 0.411 \\
\hline Four rooms and above & $11(19.3 \%)$ & $46(80.7 \%)$ & $57(15.9)$ & Reference & \\
\hline \multicolumn{6}{|c|}{ Having hand washing facility } \\
\hline Yes & $36(25.7 \%)$ & $104(74.3 \%)$ & $140(39.0)$ & Reference & \\
\hline No & $60(27.4 \%)$ & $159(72.6 \%)$ & $219(61.0)$ & $1.09(0.67-1.76)$ & 0.725 \\
\hline \multicolumn{6}{|c|}{ Ownership of latrine facility } \\
\hline Private & $37(25.0 \%)$ & $111(75.0 \%)$ & $148(41.2)$ & Reference & \\
\hline Shared & $59(28.0 \%)$ & $152(72.0 \%)$ & $211(58.8)$ & $1.16(0.72-1.88)$ & 0.533 \\
\hline \multicolumn{6}{|c|}{ Whether feaces are around the house } \\
\hline Yes & $59(33.1 \%)$ & $119(66.9 \%)$ & $178(49.6)$ & $1.93(1.20-3.11)$ & 0.007 \\
\hline No & $37(20.4 \%)$ & $144(79.6 \%)$ & $181(50.4)$ & Reference & \\
\hline \multicolumn{6}{|l|}{ Source of water } \\
\hline Piped and public taps & $77(25.9 \%)$ & $220(74.1 \%)$ & $297(82.7)$ & Reference & \\
\hline Protected well/spring & $5(45.5 \%)$ & $6(54.5 \%)$ & $11(3.1)$ & $2.38(0.71-8.02)$ & 0.162 \\
\hline $\begin{array}{l}\text { Unprotected well/ } \\
\text { spring }\end{array}$ & $11(27.5 \%)$ & $29(72.5 \%)$ & $40(11.1)$ & $1.08(0.52-2.27)$ & 0.832 \\
\hline River/lake & $3(27.3 \%)$ & $8(72.7 \%)$ & $11(3.1)$ & $1.07\left(0.28-\_4.14\right)$ & 0.920 \\
\hline \multicolumn{6}{|c|}{ Whether the family has livestock } \\
\hline Yes & $5(31.2 \%)$ & $11(68.8 \%)$ & $16(4.5)$ & $1.26(0.43-3.72)$ & 0.677 \\
\hline No & $91(26.5 \%)$ & $252(73.5 \%)$ & $343(95.5)$ & Reference & \\
\hline \multicolumn{6}{|c|}{ Ownership of agricultural land } \\
\hline Yes & $32(29.4 \%)$ & $77(70.6 \%)$ & 109(30.4) & $1.21(0.73-1.99)$ & 0.459 \\
\hline No & $64(25.6 \%)$ & $186(74.4 \%)$ & $250(69.6)$ & Reference & \\
\hline
\end{tabular}

Table 3: Environmental factors stratified by diarrhea occurrence among children.

\section{Factors associated with diarrheal diseases among children aged less than 5 years}

Multiple regression analysis was performed in order to identify factors independently associated with diarrheal diseases among children aged less than 5 years. All factors significantly associated at bivariate analysis were considered together in a multivariable analysis. Five factors were considered in the analysis. Upon fitting these factors using binary logistic regression and by specifying 'backward LR' method with removal at $\mathrm{p}<0.05$, four factors remained in the final analysis or reduced model (Table 4 ).

Children whose mothers/caretakers had never attended school were 3.7 times $(\mathrm{aOR}=3.76 ; 95 \% \mathrm{CI}=1.26-11.24 ; \mathrm{p}=0.018)$ and attended primary were 2.9 times $(\mathrm{aOR}=2.94 ; 95 \% \mathrm{CI}=1.04-8.28 ; \mathrm{p}=0.042)$ more likely to have diarrheal diseases compared to those who attended 
tertiary level of education. Children who had not vaccinated for Rota virus were about 8 times more likely to develop diarrheal diseases $(\mathrm{aOR}=8.11 ; 95 \% \mathrm{CI}: 1.84-35.70 ; \mathrm{p}=0.006)$ than to those who were vaccinated. Mothers/caretakers who reported presence of feaces around their houses had 2 times more children with diarrheal diseases compared to those reported otherwise; $(\mathrm{aOR}=2.02 ; 95 \% \mathrm{CI}=1.22-3.35$; $\mathrm{p}=0.006$ ). Children living in earthen floor houses had 1.7 times more risk of diarrhea $(\mathrm{aOR}=1.76 ; 95 \% \mathrm{CI}$ : 1.05-2.96; $\mathrm{p}=0.031)$ compared to those living in a cement floors.

\begin{tabular}{|c|c|c|c|c|}
\hline Variables & COR $(95 \% \mathrm{Cl})$ & p value* & AOR $(95 \% \mathrm{Cl})$ & $p$ value \\
\hline \multicolumn{5}{|c|}{ Level of education of mothers/caretakers } \\
\hline Never attended & $3.77(1.29-10.99)$ & 0.015 & $3.76(1.26-11.24)$ & 0.018 \\
\hline Primary & $2.84(1.04-7.80)$ & 0.043 & $2.94(1.04-8.28)$ & 0.042 \\
\hline Secondary & $1.03(0.35-3.03)$ & 0.961 & $1.00(0.33-3.04)$ & 0.999 \\
\hline Tertiary & Reference & & Reference & \\
\hline \multicolumn{5}{|c|}{$\begin{array}{l}\text { Occupation of the mother/ } \\
\text { caretaker }\end{array}$} \\
\hline Government employee & Reference & & Reference & \\
\hline Self employed & $2.02(0.97-4.22)$ & 0.062 & $0.75(0.29-1.92)$ & 0.541 \\
\hline Jobless & $2.48(1.19-5.19)$ & 0.015 & $0.77(0.28-2.10)$ & 0.608 \\
\hline \multicolumn{5}{|c|}{ Weather received rota virus vaccine } \\
\hline Yes & Reference & & Reference & \\
\hline No & $5.78(1.42-23.58)$ & 0.015 & $8.11(1.84-35.70)$ & 0.006 \\
\hline \multicolumn{5}{|c|}{$\begin{array}{l}\text { Type of the floor material of } \\
\text { house }\end{array}$} \\
\hline Earthen & $1.92(1.19-3.11)$ & 0.007 & $1.76(1.05-2.96)$ & 0.031 \\
\hline Cement & Reference & & Reference & \\
\hline \multicolumn{5}{|c|}{ Whether feaces are around the house } \\
\hline Yes & $1.93(1.20-3.11)$ & 0.007 & $2.02(1.22-3.35)$ & 0.006 \\
\hline No & Reference & & Reference & \\
\hline
\end{tabular}

Table 4: Factors associated with diarrheal diseases among children aged less than 5 years.

\section{Discussion}

This study provides the prevalence of diarrheal diseases and its determinants among children less than five years in the previous two weeks preceding data collection. Our study found that, the prevalence of diarrhea in children aged less than five years was $26.7 \%$. This was similar to a study of 2-week period prevalence of diarrheal disease among under-five children conducted in Hadaleala District of Ethiopea which reported $26.1 \%$ [7]. The finding of this study is slightly lower than the finding of a study conducted in Burundi (32.6\%) [15] and in Arba Minch District, Ethiopea (31.0\%) [6]. However, it was very high compared to the national prevalence (12\%) [13]. Furthermore, it was by far higher compared to a cross-sectional study conducted in Indigenous Batwa Pygmy in southwestern Uganda within the previous 14 days which showed $6.17 \%$ [17]. The disparity in prevalence rates may be due to seasonal variation. The data of the present study was collected in October which is a rainy season. During this period water sources are easily polluted, these sources of water are mostly utilized by households for washing of hands, household activities and even drinking especially for those using streams or boreholes.

This study indicated that mothers/caretakers level of education was statistically associated with the occurrence of childhood diarrhea. Children whose mothers/caretakers had never attended school were 3.7 times and attended primary were 2.9 times more likely to have diarrheal diseases compared to those who attended tertiary level of education. This finding is similar with other studies [6,18-22]. This was also supported by RDHS in 2014-2015 where it was revealed that the prevalence of diarrhea is higher among children whose mothers have no education (14 percent) or a primary education (12 percent) than among those whose mothers have a secondary education or higher (9 percent). This may be due to the fact that education is likely to enhance household health, good feeding and weaning practices and hygiene and sanitation practices. Education can also increase awareness about the transmission and prevention methods of diarrhea. It also encourages changes in behavior at the household level. 
Our study found that children who had not vaccinated for Rota virus were 8 times more likely to develop diarrheal diseases than to those who were vaccinated. This finding is similar to a cross-sectional study undertaken during 2012-2013 to determine the prevalence, strains and factors associated with rotavirus infection among under-5year-old children hospitalized with acute diarrhea in Uganda which found that Rotaviruses are the most cause of diarrhea in children [23]. Rotavirus is the most common cause of severe childhood gastroenteritis worldwide [24]. Rotavirus vaccine resulted in a large decline in diarrhea mortality and concluded that vaccination is the best way to prevent severe rotavirus disease and the deadly, dehydrating diarrhea that it causes [25].

Mothers/caretakers who reported presence of feaces around their houses had significantly more children with diarrheal diseases compared to those reported otherwise. Diarrhea is generally due to exposure to diarrhea-causing organisms which is mainly found in feaces. The practice of unsafe child feaces disposal contaminates the surrounding environment with human excreta which carries many infectious organisms that can cause enteric diseases such as childhood diarrhea [26-28]. This result was consistent with other reports, where environmental sanitations most often linked with the diarrhoea is refuse disposal [29-31]. Therefore, safe feaces disposal practice may be particularly important in prevention of fecal-oral transmission as children are more susceptible to these diseases and are often defecating in areas where other children could be exposed.

The occurrence of diarrhoea was 1.7 times higher in children of families whose homes had earth floors than in children whose homes had cemented floors. This is in agreement with a study conducted Saudi Arabia [32]. A possible reason for this could be that the earthen floor serves as a repository for microorganism.

\section{Conclusions and Recommendation}

The study reveals that the prevalence of diarrheal diseases was high (26.7\%) compared to National level (12\%). Moreover, multiple logistic regressions revealed that the following factors as independent predictors of diarrheal diseases: children whose mothers/caretakers had never attended and attened primary school; children who were not vaccinated for Rota virus; children living around houses where feaces present and children living in earthen floors. This finding is important because it has implications on the implementation of healthcare programs to address childhood diarrhea problems in Rwanda. The Ministry of Health and other stakeholders should increase the awareness on sanitation of the environment in order to increase hygiene level around the house (especially feaces). Moreover, the mothers/caretakers should be encouraged to fully vaccinate their children against Rotavirus.

\section{Limitation}

The occurrence of diarrhea was determined based on the reports of mothers/caretakers without the confirmation of physicians. As such the study might be affected by social desirability bias. However, the data was collected by trained research assistants. Another important limitation of the study was that the occurrence of diarrhea obtained 2 weeks period prior data collection and data collection was conducted in one month. This does not account for seasonality; hence data are not comparable either across sites or over time.

\section{Competing Interests}

The authors declare that they have no competing interests.

\section{Acknowledgements}

The authors are pleased to acknowledge the research assistants and study participants for their cooperation. We also would like to thank managers of Biryogo, Cornum, Kabusunzu, Muhima, Mwendo and Rugarama for their cooperation and allowing us to conduct our research in their respective health centers.

\section{References}

1. Scrimgeour AG, Lukaski HC (2008) Zinc and diarrheal disease: current status and future perspectives. Curr Opin Clin Nutr Metab Care 11: 711-717.

2. World Health Organization, United Nations Children's Fund (2009) Diarrhoea: why children are still dying and what can be done. World Health Organization (WHO) \& United Nations Children's Fund (UNICEF), Geneva.

3. Brown J, Cairncross S, Ensink JHJ (2013) Water, sanitation, hygiene and enteric infections in children. Arch Dis Child 98: 629-634.

4. Ahs JW, Tao W, Löfgren J, Forsberg BC (2010) Diarrheal diseases in lowand middle-income countries: incidence, prevention and management. Open Infect Dis J 4: 113-124.

5. Boschi-Pinto C, Velebit L, Shibuya K (2008) Estimating child mortality due to diarrhoea in developing countries. Bulletin of the World Health Organization 86: 710-717.

6. Shikur M, Marelign T, Dessalegn T (2013) Morbidity and associated factors of diarrheal diseases among under five children in Arba-Minch District, Southern Ethiopia. Sci J Public Health 1: 102-106.

7. Woldu W, Bitew BD, Gizaw Z (2016) Socioeconomic factors associated with diarrheal diseases among under-five children of the nomadic population in northeast Ethiopia. Trop Med Hea 2: 44:40.

8. Gedefaw M, Takele M, Aychiluhem M, Tarekegn M (2015) Current status and predictors of diarrhoeal diseases among under-five children in a rapidly growing urban setting: the case of city administration of Bahir Dar, northwest Ethiopia. Open J Epidemiol 5: 89-97.

9. Mengistie B, Berhane Y, Worku A (2011) Prevalence of diarrhea and associated risk factors among children under-five years of age in eastern Ethiopia: a cross-sectional study. Open J Prev Med 3: 446-453.

10. Tamiso A, Yitayal Y, Awoke A (2013) Prevalence and determinants of childhood diarrhoea among graduated households, in rural area of Shebedino District, Southern Ethiopia. Sci J Public Health 2: 243-251.

11. Dessalegn M, Kumie A, Tefera W (2011) Predictors of under-five childhood diarrhea: Mecha District, West Gojam, Ethiopia. Ethiop J Health Dev 25(3): 192-200.

12. Karambu S, Matiru V, Kiptoo M, Oundo J (2013) Characterization and factors associated with diarrhoeal diseases caused by enteric bacterial pathogens among children aged five years and below attending Igembe District Hospital, Kenya. Afr Med J 16: 12-24.

13. National Institute of Statistics of Rwanda (NISR) Ministry of Health (MOH) [Rwanda], and ICF International (2015) Rwanda Demographic and Health Survey. Rockville, Maryland, USA: NISR, MOH, and ICF International.

14. Diouf K, Tabatabai P, Rudolph J, Marx M (2014) Diarrhea prevalence in children under five years of age in rural Burundi: an assessment of social and behavioural factors at the household level. Global health action 7: 12-34.

15. UNICEF/WHO (2009) Diarrhoea: Why children are still dying and what can be done. The United Nations Children's Fund/World Health Organization, Geneva.

16. Black RE, Morris SS, Bryce J (2003) Where and why are 10 million children dying every year? Lancet 361: 2226-2234. 
17. Clark S, Berrang-Ford L, Lwasa S, Namanya DB, Edge VL (2000) The burden and determinants of self-reported acute gastrointestinal illness in an indigenous Batwa Pygmy population in Southwestern Uganda. Epidemiol Infect 143: 2287-2298.

18. Rahman A (2006) Assessing income-wise household environmental conditions and disease profile in urban areas: study of an Indian city. Geo J 65: 211-227.

19. Anteneh A, Kumie A (2010) Assessment of the impact of latrine utilization on diarrheal diseases in the rural community of Hulet Ejju Enessie Woreda, East Gojjam Zone, Amhara Region. Ethiop J Health Dev 24: 114-118.

20. Yilgwan CS, Okolo SN (2012) Prevalence of diarrhea disease and risk factors in Jos University Teaching Hospital, Nigeria. Ann Afr Med 11: 217-221.

21. Yilgwan C, Yilgwan G, Abok I (2005) Domestic water sourcing and the risk of diarrhea: a cross-sectional survey of a semi-urban community in Nigeria. J Med 5: 34-37.

22. Gebru T, Taha M, Kassahun W (2014) Risk factors of diarrheal disease in under-five children among health extension model and non-mode families in Sheko District rural community, Southwest Ethiopia: comparative cross-sectional study. BMC Public Health 14: 395-340.

23. Bwogi J, Malamba S, Kigozi B, Namuwulya P, Tushabe P, et al. (2013) The epidemiology of rotavirus disease in under-five-year-old children hospitalized with acute diarrhea in central Uganda. Arch Virol 161: 999-1003.

24. Tate JE, Burton AH, Boschi-Pinto C, Steele AD, Duque J, et al. (2012) WHO-coordinated Global Rotavirus Surveillance Network. 2008 Estimate of worldwide rotavirus-associated mortality in children younger than 5 years before the introduction of universal rotavirus vaccination programmes: a systematic review and meta-analysis. Lancet Infect Dis 12: 136-141.

25. Patel MM, Steele D, Gentsch JR, Wecker J, Glass RI, et al. (2011) Realworld impact of rotavirus vaccination. Ped Infect Dis J 30: 1-5.

26. Clasen TF, Bostoen K, Schmidt WP, Boisson S, Fung ICH, et al. (2010) Interventions to improve disposal of human excreta for preventing diarrhoea. Cochrane Database Syst Rev 2: 6-18.

27. Aziz KMA, Hoque BA, Hasan KZ, Patwary MY, Huttly SRA, et al. (1990) Reduction in diarrheal diseases in children in rural Bangladesh by environmental and behavioural modifications. Trans R Soc Trop Med Hyg 84: 433-438.

28. Garrett V, Ogutu P, Mabonga P, Ombeki S, Mwaki A, et al. (2008) Diarrhea prevention in a high-risk rural Kenyan population through point-of-use chlorination, safe water storage, sanitation, and rainwater harvesting. Epidemiol Infect 136: 1463-1471.

29. Heller L, Colosimo A, Antunes C (2003) Environmental sanitation conditions and health impact: a case-control study. Rev Soc Bras Med Trop 36(1): 41-50.

30. Root GPM (2001) Sanitation community environment and childhood diarrhea in rural Zimbabwe. J Health Popul Ntr 19(2): 73-82.

31. Teklemariam S, Getaneh T, Bekele F (2000) Environmental determinants of diarrheal morbidity in under-five children, Keffa-Sheka zone, south west Ethiopia. Ethiop Med J 38(1): 27-34.

32. Al-Mazrou YY, Khan MU, Aziz KM, Farid SM (1995) Factors Associated with Diarrhoea Prevalence in Saudi Arabia. J Family Community Med 2(1): 27-34 